\title{
Roundtable Discussion on Event Data
}

Ersel Aydınlı: It seems like I have all the microphones, but that doesn't mean that I will do all the talking! We have only one question, in light of yesterday's presentations and discussions that I think we have to respond to here today: how do we really apply event data to Turkish foreign affairs and foreign policy, security affairs and Turkish IR? With the help of everybody here, Turkish scholars and our international guests, we would like to spend this opportunity looking for some suggestions to respond to this. We have of course technical issues, event data related issues, as well as topical or subject-matter related issues-Turkish foreign affairs, foreign policy, and so on. Would anybody like to go first?

Özgür Özdamar: (Bilkent University) I would like to start out by saying thanks to the organizers because this has been a great conference for all of us to both learn about event data and also to think about future projects involving Turkish Foreign Policy. We were asked to prepare a bit for this workshop, so while I was reading articles about event data, I began thinking about how we can apply this to Turkish Foreign Policy studies. These are just the first things that came to my mind and they are very crude ideas, but I think I could categorize them in two ways: The first would be more a test of the event data methodology itself and the other would be about looking at the past of substantive issues concerning Turkish Foreign Policy by using event data.

Another thing that came to my mind is that of a more descriptive study of Turkey's foreign relations by using event data. For example, using event data to understand such questions as who are we in contact with the most and in what ways, or who are we in cooperation with the most, or what kind of conflictual relations do we have the most? Even that kind of a simple descriptive study, as far as I know, has not been done here. Moreover, there are some substantial questions concerning Turkish Foreign Policy and I think that event data can help us understand them. One of them, for example, is the much debated Davutoğlu foreign policy, whether it has decreased cooperation among neighbors or not. The argument often goes that since 2002, both the AKP foreign policy and the current Foreign Minister, Davutoğlu's foreign policy has decreased the cooperation with Turkey's neighbors. The countering argument is that it increased cooperation with neighbors compared to before, but there is no test using this type of data.

Finally, the other thing that comes to my mind is, as we debated a lot in the last maybe three or four years is what we call in Turkish the "Eksen Kaymasi," or basically, axis shift. The question is whether Turkish Foreign Policy is shifting its axis from pro-Western to proEastern. It seems like so many scholars feel like they have to pick a side. But if you use a methodology like event data, if you rely on hard data, you can really understand whether Turkish foreign policy is indeed changing its direction or is it the same, or is it in one way shifting but in another way not. 
Pınar İpek: (Bilkent University) I just want to add to what Özgür Hocam has already said about the lack of data, even at the descriptive level. From my field of political economy, the relationship between business or globalization and its impact after the dissolution of the Soviet Union on Turkish Foreign Policy is highly discussed by IR scholars. But they don't generally look at the impact of globalization in terms that could be studied in a comparative manner. For example, in the 1980s, especially, looking at the similar cases of Turkey with various Latin American or some Asian countries, they could look at the liberation of the markets. Then there is the question of business and foreign policy, for example, analyzing the role of business in foreign policy towards Africa. The role of business as an independent variable I think would be very interesting to study using event data. Why? Because from rational behavior we would assume businesses would behave similarly, right? What is the optimal goal - to maximize profit and to survive in the competitive market? So, yes, by sector they may differ, but overall the behavior or goals should be similar. On the other hand, the strategies may differ. If we looked at the aggregate level, associating types of behavior among the businesses in terms of style, we may observe interesting variations or similarities. There are a number of possible groups to look at. We have, for example, MUSIAD, we have TUSKO, and we have TUSIAD. While TUSIAD is more EU-oriented big business, and liberal, TUSKO is more conservative, more an Anatolian tiger type. Then we could compare TOBB versus MUSIAD. They all cover different sizes of companies and so on. When we think about these business associations, the role of data collection is a big issue. You would think that the business sector would be more cooperative and they would have handy data to share with you, but it's not always the case, as I've found myself, unfortunately, in trying to get data from TUSIAD. So, the idea of using public event data seems like an interesting and potentially very useful way of gathering data and answering some important questions.

Balkan Devlen: (Izmir University of Economics) Again thank you very much for organizing this interesting workshop. Just adding a couple of things to what Özgür and Pınar have said. I keep thinking about two things; one is the creation of such a dataset. First of all, it should be able to carve a space in Turkish foreign policy but would it also be used on the international academic scene as well? Basically, is there a possible language issue if you're using only Turkish language sources? So I'm also thinking a second track could also be a limited prototype kind of analysis created with just Turkish language sources. Such a project could actually garner funding support from some of the defense related agencies in Turkey to create a Turkish language news extracting program for event data. So, I think a two track approach in which one relies more on international news wire things for Turkish interactions but also another that relies on Anadolu Ajans or other Turkish sources, to be able to see whether we actually detect any differences or not. That might be one way to conceptualize and one way to go forward.

Another idea I was thinking of was picking an issue to explore with event data to actually demonstrate to Turkish academics how an event dataset could be used and be useful for explaining certain foreign policy issues. An example could be the Turkish Cyprus issue. Everybody out there has written on this, so everybody knows the basics of it, but using concrete data to actually analyze and pose questions about this issue makes sense and could shed light on further development. As a prototype work, it could show the usefulness of event data to the general public and then gather more researchers to work on it. 
Belgin Şan-Akça: (Koc University) Just following up on what Balkan was talking about, especially with respect to the interaction between, for instance, domestic politics and foreign affairs. In the past decade or so, one of the major debates has been that the Turkey-Israeli alliance was shattering and this is problematic. Yet some people were saying, no, that is not true, the current political party in the government is just trying to present this picture, which may not actually be the real interaction going on between Israel and Turkey. With cases like these, I believe event data will be very informative to capture the real live interactions between actors, in this case, Israel and Turkey.

Another side of event data analysis I'm also wondering about is if it is possible to actually look at the discourse and explore how certain events are being basically created by the political actors. That would also be extremely useful. In other words, not just looking at what is going on in reality, but also at what is being framed by the political actors. In terms of comparison, we may think about how issues actually are covered by the leaders or other political actors and think about the ways how we can do this through event data analysis.

On the other hand, as it was pointed out in the talk yesterday, there are some limitations. For instance, we know of some scholars who collected data on military casualties that the Turkish military has suffered since the PKK's violence began back in 1984. The argument is that the government is not revealing the real figures so one researcher needed to go around certain towns and basically survey people about whether they had lost any sons serving in the military. The same is also valid for the PKK - they may be down- playing the fatalities also. So there is also the limitation that we may be facing on the part of political actors in Turkey, and the accuracy of their reporting. How can we deal with these types of problems? This is very specific I know, but because we are talking about issues and topics in Turkish politics, this also is one of the problems that you may want to address. Especially since I think terrorism is going to be one of the significant topics covered in this project.

Ersel Aydınlı: I'll jump in and say one thing. Turkish foreign affairs and foreign policy studies are of course one major dimension. But security issues are extremely important not only for Turkey but also for the region. Take for example transnational security issues; they present huge challenges in the area, e.g. human trafficking, sex trafficking, small arms trafficking and drug trafficking. The nexus between these transnational security challenges and domestic governments is another major issue to be explored, and perhaps we could think about the potential for event data type analysis in looking at such things.

In terms of specific security issues and Turkey, of course Turkey has been suffering with an insurgency problem over the last 30 years, the so-called Kurdish question. It not only involves terrorism but also ethnic insurgency, democratization, new kinds of actors, drug trafficking, bad governance, and so on. Over the past couple of years there has been some strange type of conflict resolution taking place, but as academics wishing to have a better understanding of conflict resolution processes, our studies are limited by not having adequate information; and we seem to have a weak starting point because we don't have data. Event data may help us start exploring answers to such questions as who really are the actors involved in this conflict resolution process? How many are they? Who is talking to whom?

Haluk Özdemir: (Kirikkale University) From what I hear, I think that there is a serious issue about event data building here. I mean if government actors don't share information with each other, how are they going to share it with others? And how can we build an event data out of all of these problems? My question is more basic actually: what do we expect from 
our event data analysis? Are we expecting to have better questions or are we expecting better conceptual definitions or clarifications about conceptual issues? To me it looks like we are not going to have better questions out of having event data analysis. It looks like everyone is going to ask their own questions still and event data here might perhaps help us clarify our conceptual definitions. So I think we should ask these questions first before asking how we can apply event data analysis to Turkish Foreign Policy analysis: What do we expect from event data? If we expect the wrong things, we might face big disappointments at the end.

Saize Arsavun: ( $\mathrm{PhD}$ student) I think that event data will be very helpful in terms of showing the patterns of foreign influence in Turkey. For instance, because I study European studies, I think it would help us to create a history of EU relations in terms of negotiations, economic relations, and so on, using these terms, and potential membership candidacy, and seeing at which times candidacy was stagnating and at which times it was more enhanced. We could then compare times that Turkey had better relations with the Middle East or the USA.

Joseph Bond: (VRA/Harvard) I have just a few quick thoughts, specifically regarding the consumer of events data. It seems to me all of the discussions so far have been based on the idea of academics as a consumer for this, and I'm wondering to what degree you expect the government to actually use and understand these data. Specifically, unless there are people buying it, unless there are buyers, it won't be used. If you take anything other than the one page executive summary to a policy maker who has got some influence, they are not going to be interested. I also think it may be helpful to look around and see what other governments are doing and how they are doing it. In Northeast Asia, for example, we have been developing a system for an agency that I can't really name, but their standard is that they are not looking only for regional data, but global data. I think if you look just regionally you are going to miss a lot of stuff. I initially think the source would have to be English language, and I think you would have to understand the biases of the sources. For example, Reuters is mainly business based, whereas AFP has better coverage. One could also look at RSS, blogs and so on. I think the basic fundamental needs are to look at global events data, make active extraction, and sectorial analysis, that is, divided up economical, political, and social. I think the ability should be to do full text search on terms like 'PKK'. One should be able to immediately pull up those directly. I also think the research questions should really drive everything, but the events data analysis, and the system, for lack of a better term, should be able to provide the academic or policy maker analysts with all of the information needed to address specific research questions.

Reşat Bayer: (Koc University) I agree that there is overall a need for more systematic collection regarding all social science matters including work on Turkey-related issues. Event data could be one way. With any sort of data collection, besides initial gathering, we also have the issue of updating these things, without which the usefulness of the science specific academic research question will fail. Is there going to be enough of either academic or policy initiative to continue its updating? And how might they actually go about doing this?

William Lowe: (University of Mannheim) I have been listening to a range of problems that have come up and will try to put things in useful order here. It seems like the substantial problems that people are talking about fall into three types, some of which require more work to do with data analysis. What I'll do is sketch out what I think those dimensions are and how to get through them. It seems that some of these questions are international and some of them more local and domestic. You have the language material issue, which 
in some sense is easy. There is also an interest and a difference of focus issue; are you interested in business organizations and domestic operational or international operational, are you interested in security? That kind of thing. And finally, the other dimension is whether one is interested in events in the past or more contemporary up to date stuff, or even more ambitiously, forecasting, a sort of temporal scheduling thing. So, everyone has been sort of dropping more of the substantive questions to that three-way categorization.

I guess there are two ways you could be thinking about choosing a first project and making it more concrete. One thing we could follow is the much used method of looking at what will get you the things you need with the least effort. So it seems like something international, and something security related will be in some sense the easiest sort of topic to do. That would be the instrumental approach to a first project. I guess the more academically interesting thought would be to say, okay don't choose the easiest one, where the data is more relevant in the developmental time period, but choose something that would possibly have the most impact. Curtis Signorino: (University of Rochester) All these comments suddenly seem like event data analysis is, it seems almost a little vague or nebulous or magical somehow, and that this concept will solve things for us. One of the things I like to hear is: what is the question that you want to address? Not just, let's collect a dataset of everything, because that is going to be impossible. What's the question we want to address frequently in analysis, what is the research problem, and it seems like there are many questions that people want to address. Once you have the question down, and once you determine whether your consumer is government, or academic, then you can use various things like; in academia, the theories you want to test define the sense of variables that you want to collect. Because again, you can't collect everything. From my own perspective, looking at public data, I wanted to estimate structural games and I went to have datasets to do that. What I found was people who had collected the data had massive amounts, but hadn't done it with an eye towards games or sequence. So much of the data I wanted actually never aggregated. So, what is the question and what is the initial theoretical framework, do you want to test competing theories at least for academics, or corporate Turkish structuring, what will you collect? Once you can answer those questions, there are all sorts of tools you can use, all sorts of either web extraction, either LexisNexis, or getting a bunch of research assistants, who you think will actually collect the data. And then there are tons of techniques that people have now to gradually deal with the analysis. But it seems to be the hard part to figure out what you actually want to collect and why.

The other concern I have comes down to who is the funder and how politics will play a part in how certain variables are coded, and will that affect the academic work. For example, with Northern Cyprus interstate disputes, one might imagine that Greece and Turkey might have different opinions on who either initiated the dispute in Cyprus. I can imagine funding by governments can be a very touchy issue.

Sean O'Brien: (Strategic Analysis Enterprises) The bureaucratic policies in Turkey are very similar to what we have in the United States, where not only do agencies not talk or share information with each other, but even within organizations. What is interesting is often you will find that people within these components desperately want that perspective because they won't share with other people, and no one is sharing anything. So what we find is a chicken and an egg issue. What we found in terms of funding is that nobody will give us funding unless we demonstrate there is a value. And it is difficult to demonstrate value until you have 
funding. What I would recommend is, as it worked well with us, we chose an issue that could provide value to at least one of these agencies, so at least that provided a kind of missing perspective that they were not getting from others who are not sharing with them. In doing so, you really need to carefully analyze the bureaucratic political landscape, because I found, unfortunately, that when you open one of these doors, another closes behind you because you have created another bureaucratic enemy. But if you start small like that, and you get at least one constituency behind you, you can then add others as you go. It's kind of a slow process, but it is working with us. As long as you make yourself indispensible, they become sort of dependent on that analysis or that new perspective that you provide that they can't get elsewhere. And we found that's what guarantees the funding.

Ersel Aydınlı: The customer related issue is very important because that is also linked to the sustainability issue. We seem to have an opportunity, but I don't know how long it will last. Turkish foreign policy is expanding in the Middle East and if we could ever tell policy makers, for example, there are massive numbers of non-state actors that are driving things in the Middle East, and we can make analyses that will let you know how much more important individual ones may become, country by country even, and how this might affect certain countries' foreign relations, they would love to know this.

For now, it looks like our debate revolves around three main issues: What are we going to really ask - in other words, what are our research questions? Next, the customer issue, how are we going to institutionalize the demand in our work? And finally, data related issues, problems with the data, technical questions and so on.

William Lowe: I was a little nervous when I was hearing the last couple of comments. Purely from an academic view, I think it might be useful to distinguish whether and to what extent you are a contractor, to what extent you are an agency, to what extent you are an academic here. What I mean from an academic point of view, one wanting to be able to offer people information about who the salient actors are going to be, and so on. That will be a primary thing, and one might be able to offer the more contractive agency type benefits as a byproduct.

Ersel Aydınlı: Synchronization I think is obviously the big challenge. We are in it for really academic purposes. Yesterday we tried to emphasize this. For example, if I personally had that type of data about the larger Middle East, I would like to work on alliance theory, and the sub-state actors in central alliance theory. Yes, but as you said, it has to be done in a way that academic necessities will be there, but an institutionalized sustainability of the whole thing, and the funding etc. has to be there too. And of course then the ethics come in to it. And you start thinking about all other things that all come into it.

William Lowe: What I was trying to say wasn't really thinking about the ethics here, but in the sense that having a research question would allow you to put this in a reasonable stance. In an academic research question, the more important idea is on the data collection, which could potentially be endless otherwise.

James Yonamine: (Pennsylvania State University) I think a lot of people are trying to get at technical questions, and if I had another half an hour to present I could have showed that there are many ways to formally extract data. Event data, in other words, actually capturing the "who did what" interactions. A lot of questions are coming out of Turkish foreign policy's evolution over time. And now you might be looking at these specific events, but it may not be as important as rhetoric and the speeches on content analysis approach. I think the key that is 
going to tie a lot of this data together is that it's based on open source, extracted through some oral process that you have coded through a rigorous process, and is more or less objective. The second point I want to make is that I think it's going to be critical, whatever type of project you guys come up with, is to consider what an existing event data project could spit out very quickly. So, the IQ project has big dictionaries with many actors as we could find in almost every country in the world, and that can spit out data on Turkish interactions with every actor in that data set for the last 15 years and you could get data in literally a day. In general the better base for Turkish resources is to create something that is inherently value add-on programs. Whether that's linguistic, or additional subtitles I'm not sure, but I think that would be credible.

Pınar İpek: I think when we try to define major research questions like the three dimensions you have listed, we should consider the interactions between these different subfields in security. I think there is a tendency to treat them separately as if they were mutually exclusive, which they are not. So, we may try to come up with research questions that overlap. For example, security and development. Specifically within security there is terrorism. You may think the last relationship between security and terrorism is business, but I think there might be one and we might observe different factors related to Turkey and a new environment given the importance of energy infrastructure and the types of threats given to different involvement of actors. What are the differences in attacks when there is a foreign firm versus a state-tostate level relationship between firms? Or, what were the patterns of terrorism before a big foreign investor entered the picture and after? This is not just in Turkey. In central Asia right after the dissolution of the Soviet Union, I would argue it was influential agents, sub-level state agents, influencing American Policy. What if the pattern of security and development is affected by the existence of different sub-state actors, let's say TIKA in Syria, in Africa. Or in the lack of those sub-state actors. Even before and after, other actors were there, not just Turkish actors, but in American issues like in Iraq, there is tons of different agents supported by different foreign actors. So what are relations like after and before terrorism and security, or negotiations and level of negotiations before and after, was it interest maximization or is it lack of interest sharing?

Reşat Bayer: I want to come back to something that James actually pointed out a while ago which is this issue of value added base. When I was reading the Aydınlı, Tüzüner, Gültekin piece, basically one thing that was mentioned was that you already have a dictionary of actors. There is a list, a clearly complete list out there and perhaps something that could be a practical manner is to see what is already out there and to see in relations to these actors that you already specified, how much of these are already covered by some of the various sources that you already mentioned, like different people, and to see exactly how many actors are you bringing and how many have already been covered for the time spam that you are interested in. Maybe you might find that the material is already covered well enough for you and your purposes. Then you might actually want to press on a different language issue or to further diversify the actors to include political economy, migration issues, and so forth on a more developed sense of security.

Ersel Aydınlı: The last suggestion I think is really key. One of the problems and therefore 
one of the first things that we would have to do is to bring in all the existing works related to Turkey at least and then compare it with ours. In other words, to make a comparative data building.

As we all kind of agreed more or less, there are three clusters, and we've discussed how we need research questions, we need institutional support, and we need to develop the data collection, processing and all that - the technical issues.

Imagine that our broad research area is the foreign policy and security outlook of Eurasia; from Russia to North Africa, from the Balkans to China. Imagine that our task is to understand the foreign policy and security outlook, the patterns of foreign policy activities of these countries with each other and also, if possible, the security outlook on cooperative and conflictive matters. And imagine we have a customer, we have money. How should we go about doing this? What should we do? So, if this was our mission, and if we had five years, and money, how should we get it right and how should we start and proceed so that we wouldn't be disappointing either ourselves as academics or our customers. How can we ensure that the quantitative matters in event data would make a nice entrance into Turkish scholarship and Turkish analysis?

Balkan Devlen: I would like to add to what was said before. What we need to look at first is what is available out there, to see what sort of data we have in existing datasets. Then we need to see their deficiencies and to see in which we have limited data. Then we can focus on those issues. Second of all would be, again this is just an assumption, that one of the major deficiencies would probably be related to the scarcity of local resources from much of this region in this global data set. Therefore, developing a necessary mechanism to gather either local language or English language, but local sources in these countries, to provide richer data and then go forward with that I guess.

Pınar İpek: I would look at the major sources, for example, the newspapers, major coverage, and even the foreign ministries. I would try to come up with the most visible topics and then the actors at the sub-state level especially. And then start the research question with theories, academic levels, groups, and look at which topics will be cooperative and which topics will be conflictive as a start.

William Lowe: I guess it's kind of obvious in these projects, but when we look at projects; they look at what they are going to do at the end. So I guess the first thing I would say would be to figure out how you can release something to someone earlier on. What is the schedule, from the academic front all the way to the policy mechanism and possibly the tools for it? Keep the schedule slightly front loaded so that people can see things happening.

Belgin Şan-Akça: Referring back to what Curtis was saying earlier, definitely we can't collect data on everything, so there is a need to narrow it down. We have to think about the topics that are really on the security topics that will be appealing to government agencies, but from the beginning, the data development project in my opinion should be developed in such a way that it appeals both to academics and policy makers. Maybe one other strategy could be to think about which other organizations or institutions, this could be international organizations too, that this data could be appealing to, and start communicating with them. Try to understand their needs. I don't know how broad you want to take this scope, but it could be interesting to engage some European Union agencies as well.

If this is going to be merely funded by the government, I have doubts about two things. 
may not be interested in topics such as human rights, but if the data is out there and funded by the government, for instance GTB data is funded to a great extent by the department of homeland security, it is widely used, but some people will argue that it is funded by the U.S. government, and we know some scholars who don't like things that are funded by government agencies. So, that could be one of the concerns. Obviously, we don't want the data to only be used by Turkish scholars, but also by an international audience.

On a technical front, someone was talking about for instance the Kansas State University system for event data analysis. I found it very complex and felt it would take a long to figure it out. So, from the beginning, whatever is done should be arranged in a way that has a more user-friendly approach.

Joseph Bond: I guess all I want to say is that I would encourage everyone in a project like this to inter-commission; to check out what is out there. I know for example there is a project called European Media Monitor, which is quite large and I think they have spent well over a hundred million dollars developing it. PC developed it. We worked with them, and it is an amazing system. I know from working in Africa, it is now used there. It operates in 27 languages, and it is quite an amazing effort. They do this social network analysis, and there is this component that is data analysis. There are incredible resources out there. So, I mean, don't reinvent them. A lot of these resources are free to anyone who wants to use them.

Curtis Signorino: Just a couple of thoughts; the one concern about the hypothesized consumer and the funding agency. If it is a governmental funding agency, with specific priorities, I think that everything that Sean suggested is really terrific advice. On the other hand, in the U.S., we are fortunate to have government funding agencies for academics like Natural Science Foundations that do help. Although there are not many cases of political science getting funded by these. But, in that case, the customer is really the rest of academia. I have served on NSF review boards, the reason something gets funded is because it provides that value added for the rest of academics to do their research. I think one of the things that is attractive in the American national election strategy is they provide the ability for other researchers to submit questions as part of the study. So it's a balancing act in this case for you guys. But, you might consider if you are interested in more buy-ins so to speak, from other academicians, to people in this room, other Turkish academics, we can include a regresser and an independent variable and dependent variable and what would you like to see us collect? We may not be able to do it because some variables are harder to collect than others, and we need a balancing act of being able to maintain the scope of a project, etc., but for that NSF system, where your customer is a bunch of other academics saying yes, you should fund this, that's a great way of getting some buy-in there.

Reşat Bayer: Also you should think about the issue of what sort of media types interest you. Yesterday there was reference to Twitter, Facebook, and others. Depending on the research question at hand, those might be very useful, or perhaps really not at all. But a different thing that is on my mind is the issue of constructing measures and how does one construct measures when you are dealing with Twitter or the Facebook world? What sort of special problems, if any, would that create for us? With the hundred and forty-four characters or whatever it is, what sort of constructional measure does there need to be engaged in based on the concepts you have on your mind and how to relate those two so that the concept and the constructions really do match up on a high level? And I wonder if these new elements such as Facebook, Twitter, etc., while useful for some purposes and policies, might be creating 
much more difficult problems as well. Maybe the idea of Twitter and the Tunisian revolution really was slightly exaggerated perhaps. These are just things that came to my mind about this media question and how to think about constructing and thinking about concepts as well. Ersel Aydınlı: Have they ever been included in any of these data sets? How was it?

Sean O'Brien: Not good. First of all, when we tried to get Twitter feed, Twitter now has a business model where they charge you a lot of money to get access to their feed. But we found someone who had paid that large sum of money and we just wanted to do some experimentation on it. We were experimenting with our sentiment analysis tools, so we wanted to extract people's sentiments towards different products and towards different issues. And we found it was just garbage for the most part. It was advertisements, it was spam, it was links to various different things, and out of five thousand Twitter instances, we found one legitimate sentiment expression. There are various business companies that claim to mine that information for corporations that want to know what people think about their products. And corporations apparently pay them for that, but when I ask these companies, how do you know whether the data is, or what you are extracting is accurate, they say, well we don't really know.

Ersel Aydınlı:You know, our president even has a Twitter account. When the number one person is into it, people seem to think that it must be influential.

Özgür Özdamar: I have a question about your hypothesized customer. I was just wondering. Well, that is kind of important because all of the other details that we are discussing now from Twitter, Facebook, to data feed from other things will actually be shaped by what kind of a customer you want, and what the customer is asking for. And I was wondering whether we should be also talking about that.

Ersel Aydınlı: Imagine that it's the Foreign Ministry, or imagine it's TUBITAK. You know, TUBITAK is our Turkish NSF. If it's TUBITAK, then it's more possible we can get this available for the scholars from now and within the next ten years. If it's the Foreign Ministry, you can imagine what they would want it for. The Foreign Minister is now building up a new Foreign Ministry; they have built an academic building, thinking that they are going to be the next Ottoman Empire or something. They have the money. They have interest in knowing more about this region, so it can be the Foreign Ministry, it can be TUBITAK.

Özgür Özdamar: Okay, I think that is really important to know that about our specific imaginary friend. All the other questions that we have been talking so much about will be guided by who our customer is.

Ersel Aydınlı: But, does it have to be that way? I'm not sure that it does. This is the first attempt, we will and we would have a lot of leverage still in how we would do it because it would be more like experimenting for them. They haven't done it before. They don't know what to expect really. I think they would trust us and say alright, am I going to be able to have a quick analysis about this region, these patterns? That is what they would be interested in. For example, a deputy secretary might say, can I just have my policy planning chief talk to you guys and get a quick analysis so that I could carry it to the Foreign Minister tomorrow, or in two days? Or imagine some event in which Turkey runs into a problem with Iran, can I get a quick understanding about even that event's sub-components in Iran? How are they relating to Iraq? How are they relating to the Iraqi Kurds? For example, they would be interested in such things. But if it is TUBITAK, that gives us of course a much larger kind of relay for our academic purposes as well. 
Özgür Özdamar: Well, I think we are presuming what the customers would want from us. There are two ways to go for this. I mean, it is like the Steve Jobs way that says that people don't know what they need until you tell them, and this is kind of what we are doing here. But the other way is the more typical way; you hire a survey agency and have them go ask people what they want. So, I was just thinking for this session, we cannot bring in people immediately right now. We at least have people who are working for the government. Who are in the subset of academics and government officials? I was just wondering whether we should ask those people in the subset what could actually a government agency need from a bunch of people like us. Otherwise we have to try to get the understanding from the other way; we put words in other people's mouths.

Ersel Aydınlı: It's not necessarily us putting words in their mouths. We have been in touch with them, we talked to them on various occasions, and we have some idea of what they want. For example, you know every Foreign Ministry has bureaus. They have bureaus for, for example, intelligence policy. They know that it's not very active, and they would like to have a much more systematic, sustainable, long term institutionalized something that would be available. If you listen to them, they are not even interested in just getting it for themselves today, the Minister himself is a former academic in Turkey, and the deputy and undersecretary would like to have something even for the future. But you are right, we are also assuming a little, but we have to. But right now we are learning that, from this discussion, we should go check with them in a more systematic way.

Cihangir Baycan: (Turkish National Police). So, after a full day, although there are some challenges and difficulties for these data modeling, I have seen that we can have good data to look at the history of any events or the relationships. We can use those kinds of data and create our policies for our positions for the future events. We may not be able to forecast events, for example, when a demonstration will happen, but we may be able to create policies for how to act in different scenarios. In that way, I believe it could be very beneficial.

Sean O'Brien: I would just like to reinforce some things that were said here. First of all, it is possible to identify issues that are both of interest to the academic community, that attract NSF funding, but are also policy relevant and attractive for government funding. For instance, forecasting conflict is important intellectually, academically. There is a way to assess the adequacy of our models, and is also very relevant to government agencies. So if you were to choose an issue to begin with, one that allows you to leverage existing things off the shelves, whether through IQS, Tabari, VRA, and master those things, and identify some scenarios you could apply to Turkish foreign relations, and then demonstrate those to your potential customers, that would be something you could do with a little bit of time but very little money. To at least get started, to socialize people and begin to educate them a little bit. And then also identify the deficiencies in these things for which you seek funding to further enhance them so that they would be more useful and specific to the kinds of issues that you want to address and that the Turkish government would like to address.

Pınar İpek: Even in the funding stage, before even the proposal writing process, we should go to the major potential customers, like the Department of the Interior, the Ministry of Foreign Affairs, some diplomats from key regions, the media, and so on, and ask them, make a customer oriented type of needs survey. We seem to be turning to a wrong direction. As if we are trying to fit event data for what we can do with event data. It should be the other way around. What are the major transformations in the world, and how does Turkey fit into 
that? And given that, does event data help my purpose? This is the framework any agency in the public policy sector would act in. I had some experience in the Ministry of Health in my early post-graduate work. They have enormous data across time. That is perhaps one of the interesting agencies that uses statistics. They prepare hospitals, and immunization centers, they analyze health threats by age groups, by seasons, by regions, and they try to share it with the Turkish health infrastructure to answer questions like, what kind of investment needs to be made in doctor training? What are the most frequently seen diseases in Turkey? Do we need that many cardiologists, or public health specialists, and so on? So, with a similar logic, we could ask, what are our problems? When can we use event data? The problems are given from the agency perspective.

Ertan Efegil: If you consider research, foreign policy analysis theories, first of all they need policy options. For example, before crises, the policy people want to know what the policy options are. They need information about the case. If you provide that, they will be your customers.

Haluk Özdemir: I am again a little confused about what we are talking about here. Aren't we then collapsing into basically not two but three parts? Are we planning on using existing datasets for our analysis? Are we going to build a new dataset? Or are we going to contribute to the existing dataset in Turkish? So, I don't know which one we are discussing here. I think we need to clarify first what we are going to do because if you decide on this wrong, then the things we are going to discuss aren't going to be right either. I think we have mentioned all three possibilities and all three are different from each other.

Ersel Aydınlı:We would be doing all those actually. I don't think they are necessarily very separated from each other. We would be building up a data set, but by first visiting the other data sets and bringing relevant stuff from those into our own for our own type of questions. Our own questions that we generate from our own interests, or the customers' interests. And for again our own purposes, which would include not only serving to the policy makers, but also to the advancement of the quality of foreign policy and IR scholarship in Turkey. That is more or less how we would be doing it. We would build up probably our own data set. We really should not reinvent the wheel, but on the other hand we have to take all kinds of country specific interests into consideration. Therefore, I think that we would have to go for creating something custom designed for us. We shouldn't be copying a dictionary that already exists somewhere.

Haluk Özdemir: So we will just be looking at the Turkish literature? Turkish news sources and academic existing data sources?

Ersel Aydınlı: Most probably, but we don't know at this stage, we don't know how different they are. Imagine the question I proposed earlier is a real question we will look at. All kinds of complications can emerge. For example, we would want information about Iran, but there the newspapers are largely in Farsi. You would also have to have somebody who could tell you that which ones of those news sources are closer to the opposition, and which are fully supporting the government. Then there's the question of what other datasets exist for Iran, and what have they looked at. Which sources that they covered? Because it is so complicated, that is why we are having all these discussions. Then, the interested body, either the research council of Turkey or the government will agree to it or not. For now, we are trying to define the parameters of the proposal in a sense. So, that it would make sense to ourselves and also to the possible customers. We are also trying to identify our own human capital as we go. 
Who are we? How much can we do? And that doesn't have to be exclusively in Turkish at all, we are imagining an international team still for this.

James Yonamine: I had an idea or thought that was along the lines of the last two discussions. And the question that was posed was, how are we going to pay for it, how are we going to go with owning our own data system? And I would suggest that the first question that was addressed to you a little bit before that, is how do we build an event data community within Turkey so that we know very thoroughly what is out there. One way to proceed is to get some questions from the government, and the academic community can put forward some questions. You can post them online and make a competition to see who can answer these questions best with what is already out there. In that way you can really understand the limitations of what exists. As for the point on medical forecasting, that is the easiest to do. Georgetown University already has a very rigorous program that is forecasting health issues in like sixty languages around the world. And the geometric European media monitor, they already provide very rigorous network analyses of interstate, potential interstate of European countries. Because there is so much research out there, I think that should be the first step.

Balkan Devlen: I think one thing that is emerging is that a good project should have differences and components that can actually move forward relatively independent of each other. With different things like funding, as Sean said, it's a chicken and egg problem. If you can actually divide these things into a couple of components, say one group dealing with the available data research with limited funded and limited human capital, and can actually provide a separate prototype and demo to shuttle, something sensational or something that would capture attention, but do this with the available resources, so they can move forward at the same time. You can have different components including creating a community, looking for a local language, computer programming aspects etc. that could be integrated eventually at a later stage, once you actually demonstrate such a value from these separate components, I think that would first make things much easier.

One simple approach for the policy makers would be just to use the available data to see if there was any escalation in terms of the discourse and in terms of the events that could have signaled an upcoming instability within Israeli-Palestinian relations. If you can see something like that, you can then say, look, there is this data that shows this. If you had known this and if you had actually used this, you wouldn't have been surprised after your return from Israel that a week later Israel would conduct an operation in Gaza. That would be something that would capture the attention of the policy makers. Then you can go on and say, we also have a proposal for you which we can actually develop this further and extend it and customize it for our needs. So that kind of model approach could gather more support and make things move a little bit further I think.

Özgür Özdamar: I also changed my mind about the first approach. I think it should be mixed, Balkan, and you actually are right. If you approach the policy makers in the way that I suggested, and asked them "what do you really need?" probably they would say my field analysts can already tell me all of this so I don't need your new methodology. Perhaps a mixed method like what Balkan describes here would be better. We should be more prepared and tell them, look, these are the things we can do, and you can even pick from these or if you need something new, you just tell me what kind of an approach you want. And I think that the most general way to describe what we discussed here is to say we can offer reliable data analysis about the regions surrounding Turkey, both the state and non-state actors. That 
would be the way to present it. And I think also the Turkish officials would be interested in what is going on inside of Turkey and what Turkish actors, and different actors are doing internationally. Like the NGOs, or political parties, or governmental agencies because even the governmental agencies one of them does know what the other is doing exactly and in international relations or other things. So, I think a kind of a mixed approach would be of course useful.

Cihangir Baycan: I agree with Balkan and Özgür, they will react like, we know everything. Believe me, they know most things, or more things than the newspaper give you. But the key point to what we can serve to the policy makers is how to analyze it. How to create new perspectives. This can be the product of this event data analysis.

Ersel Aydınlı: I think we shouldn't keep you here too long. I really would like to thank all of you for coming to this workshop. Personally, I have a much clearer picture of how we need to proceed from here. And that is exactly one of the major reasons why we wanted to do this. It was also a great chance to bring people together, to create new contacts and new cooperation possibilities among us all.

Musa Tüzüner: I would like to also thank all the participants, our international and Turkish scholars, our research assistants, and the organizing agency members. We had a goal of bringing together international scholars to see what they are doing, with Turkish scholars. There has been a lot of information shared, and questions raised, so I think we are on the right path. Thank you all very much. 